\title{
A SAÚDE PÚBLICA E OS SEUS AGENTES EM PORTUGAL: O CASO DOS BOTICÁRIOS (1521-1557)
}

\section{Isabel M. R. Mendes Drumond Braga}

1. A saúde pública constituíu, desde cedo, uma preocupação, quer dos particulares, quer da coroa. Se é um facto que, desde o século XII, algumas pessoas deixaram certos bens para fundar ou manter hospitais ou outras casas de assistência destinadas a pobres e a viajantes, além das instituições espectificamente dirigidas a doentes, como gafarias (1), também é verdade que a partir dos finais de Quatrocentos os hospitais se caracterizaram pelo acolhimento que forneceram a enfermos, constituíndo uma preocupação dos monarcas, que aprovaram compromissos e fizeram dotações (2). De qualquer modo, esta situação não obstou a que o final da Idade Média fosse de crise para os estabelecimentos de assitência (3).

Na época moderna, D. João III, dando continuidade a uma prática anterior, preocupou-se com a preservação do bem estar das populações, nomeadamente através da designação dum provedor-mor da saúde, a 27 de Setembro de 1526, nomeação essa que recaíu no desembargador Pedro Vaz, após este se ter deslocado a Itália no intuito de estudar as soluções adoptadas em Roma, Milão e Florença face às epidemias (4). Aliás, refira-se que as pestes desencadearam, desde a Idade Média, uma série de medidas preventivas e de emergência levadas a cabo pelos municípios (5), com o apoio da coroa, que veio a punir aqueles que viessem 
de locais pestíferos (6) e tentassem entrar em zonas sãs sem a devida autorização (7).

Para levar a bom termo a necessária assistência, eram necessárias várias condições. Desde uma cobertura hospitalar suficiente (8), passando obviamente pela existência de profissionais de saúde qualificados, e terminando na própria educação dos doentes, que nem sempre recorriam aos físicos e cirurgiões, mas às bruxas, curandeiros ou mulheres de virtude (9). Não eram estes problemas de fácil solução. Sabe-se que foram aumentando em número os graduados em Medicina, cuja preparação se fazia no reino e no estrangeiro, nomeadamente nas universidades de Salamanca (10) e de Montpellier (11), vindo estes posteriormente a pedir equivalência dos títulos obtidos (12). Mas sabe-se também que, após a transferência definitiva da universidade portuguesa de Lisboa para Coimbra, em 1537 (13), os professores de Medicina não acompanharam esta mudança, vindo as cadeiras a aparecer à medida que apareciam mestres idóneos, alguns dos quais estrangeiros, tal é o caso de Rodrigo Reynoso, um Castelhano que em 1545 ocupou a cadeira de Prima (14). Não será este o único, basta pensar em Martim de Azpilcueta e em Afonso de Guevara (15), este último - ou os seus discípulos de Valladolid ou Guadalupe- terá sido o introdutor do ensino da anatomia e da dissecação de cadáveres em Portugal (16). Recorde-se a propósito que houve um importante centro de aprendizagem de cirurgia em Guadalupe (17), o qual foi frequentado por Portugueses (18), e de onde vieram médicos, nomeadamente para tentar curar a rainha D. Maria, mulher de D. Manuel (19).

Mesmo assim, a prática da Medicina por pessoas não qualificadas era muito vulgar, vindo. a dar lugar a situações de risco. Por exemplo, em 1550, Catarina Afonso, a Castelhana, uma viúva de 60 anos, moradora em Barcelos, foi condenada a três anos de degredo para o Norte de África com baraço e pregão, vindo a pena a ser comutada em degredo para o couto do Sabugal, porque «se fazia mestre não ho semdo e que curava de muitas irnfirmidades e principalmente destes malles de boubas as quais cousas fazia com beberagens que dava aos doentes", tendo vindo a morrer várias pessoas (20).

De qualquer modo, o monarca também permitia que pessoas sem frequência universitária curassem certas doenças, desde que fossem examinados pelo cirurgião-mor. De entre estas temos algumas mulheres. A 15 de Fevereiro de 1544, Leonor Afonso, moradora em Rio Torto, termo de Chaves, obteve carta de cirurgia (21). A 19 do mesmo mês, Graça Gonçalves, moradora em Matosinhos, foi autorizada a «curar de cousas quebra- 
das e fora de seu luguar e asy de quallquer outras curas de solorgia» (22). A 30 de Outubro, Madalena Fernandes de Castro, moradora no Porto, teve autorização para "curar destes males de boubas e de curymentos e chaguas» (23). A 30 de Agosto de 1552, foi a vez de Isabel Alvares obter carta de cirurgia, só válida para exercer tal actividade no Vimiero e seu termo.(24). Todas estas mulheres (25) foram examinadas por Mestre Gil. Por seu turno, a 24 de Abril de 1532 João Fernandes solicitou a D. João III autorização para continuar a curar e benzer «todas as pessoas e alymaryas de dor de caes danados» (26), numa clara mistua entre crendice e medicina.

2. Para a cura das doenças dos foros físico e psíquico (27) eram, pois, necessários, físicos e cirurgiões (28), mas também barbeiros, parteiras e boticários (29). Destes últimos, nada sabemos antes do século XV em relação a Portugal, se bem que Medicina e Farmácia tenham estado juntas, uma vez que, de início, os clínicos preparavam os medicamentos de que se serviam (30). Em Castela, aparecem referências a boticários desde 1217, sabendo-se que a formação dos mesmos se adquiria trabalhando em boticas ou em hospitais durante um certo tempo, ao fim do qual o candidato a boticário se deveria apresentar ao Tribunal del Real Protomedicato, o qual passava uma carta de exame (31).

No que se refere a Portugal, uma lei de 9 de Março de 1450 determinava que os municípios, através dos rendeiros e recebedores das sisas, visitassem as boticas (32). Mais tarde, em 1497, o físico mor, Mestre Rodrigo, elaborará o primeiro regimento dos preços dos medicamentos (33). Em 1515, no regimento do físico-mor, proibe-se aos boticários a venda de mezinhas a preço superior às do boticário da corte (34). Antes ainda, em 1497, a câmara de Lisboa decretou uma série de prescrições no intuito de salvaguardar os interesses dos utentes (35). Quanto ao cargo de farmacêutico do Hospital Real de Todos os Santos, sabe-se que foi regulamentado em 1504, sendo plausível que o boticário também vendesse mezinhas aos doentes que não estando internados se íam apenas consul$\operatorname{tar}(36)$.

Estudar os boticários, implica também estudar as boticas, as antigas farmácias, embora o termo tenha começado por ter um significado mais abrangente (37). Nelas se guardavam xaropes, águas, electuários, solutivos, pílulas, emplastros, unguentos, óleos, ervas, pós, conservas e sim- 
ples, a avaliarmos por um rol de preços de 1572 (38). Ao boticário cabia manipular os fármacos segundo as indicações dos médicos. A partir de 1498 , no intuito de facilitar os doentes e os boticários, os físicos foram proibidos de passar receitas em latim (39). Na terapia, além da dieta e da cirurgia, a medicação era fundamental, verificando-se muitas influências da farmacopeia antiga e nomedamente da grega e da árabe, bem como o recurso as plantas (40). Aliás, o uso destas foi uma constante (41), quer pelos boticários, quer pelos curandeiros (42).

No entanto, as Ordenações Manuelinas proibiam a posse de determinados produtos, salvo aos boticários, os quais só deveriam vender certas substâncias a pessoas idóneas que não as fossem dar a outrém. Tais produtos só deveriam ser utilizados em mezinhas segundo ordem médica. $\mathrm{O}$ desrespeito do estabelecido implicava o pagamento de uma multa de 50 cruzados após a primeira infraç̧ão (43).

No caso da farmacopeia portuguesa da época moderna, verifica-se uma grande influência de produtos provenientes da costa ocidental africana (44), do Brasil (45) e também do Oriente, facto a que se ligam os descobrimentos e a expansão. Realmente, o contacto entre povos e civilizações diferentes, promoveu a circulação de produtos e técnicas que até então eram exclusivas de certos espaços (46), permitindo salientar o aspecto racionalista pragmático-experimental da cultura deste período (47), o qual se traduz, no campo da farmacopeia, em obras como os Colóquios dos Simples e das Drogas de Garcia da Orta (48) e o Tratado das Drogas e Medicina das Indias Orientais de Cristóvão da Costa (49).

Contudo, se importa não esquecer o enriquecimento europeu ocorrido em consequência da presença portuguesa no Oriente, também deve ser salientado o facto dos Portugueses levarem para outras paragens os seus fármacos, os seus métodos e as suas mezinhas, se bem que o clima e a morosidade das viagens levasse, por vezes, à deterioração dos produtos. Disso mesmo deu conta Tomé Pires, em carta escrita de Cochim a D. Manuel, em 1516: "Nom envie Vosa alteza de laa nenhuas mezinhas compostas pera qua de nenhuma sorte e comdição salvante trementina alvayade azinhavre [...] pois que as cousas que as façam os buticairos e solorgiaes e físicos [...] e tudo se gasta debalde tudo se qua resolve em cousas que qua ha e encurtara vosa alteza a despesa das mezinhas pois que nom aproveytam por pasarem grandes quenturas com per ser qua outro clima» (50).

Mesmo assim, e quer beneficiando dos produtos existentes nos locais de acolhimento, quer levando do reino, os Portugueses foram abrindo bo- 
ticas, anexas aos hospitais, nos diversos locais onde se fixaram. tais como Cochim, Cananor, Goa, Chaul, Malaca, Tidore, Diu, Funai, Arzila e Congo (51). Há ainda a registar as boticas que seguiam a bordo, umas caixas de madeira ou de folha de Flandres, de tamanho variável onde se guardavam os medicamentos cuja responsabilidade competia ao boticário (52). Alguns dos produtos que seguíam nas naus, e que hoje são conhecidos (53), nem sempre se mostravam eficazes no combate às doenças. Estas boticas eram utilizadas nas viagens com destino ao Oriente, à costa ocidental africana e ao Brasil, e também nas que os Castelhanos empreendiam ao Novo Mundo. De facto, a primeira farmácia da América Espanhola partiu de Sevilha, em 1514 (54).

3. Cabe agora determo-nos sobre os boticários portugueses durante o reinado de D. João III, isto é, entre 1521 e 1557. O modo de obter carta

\section{Quadro I}

\section{NÚMERO DE CARTAS DE BOTTICÁRIO POR ANO}

\begin{tabular}{|c|c|c|c|c|}
\hline & . & & & : \\
\hline & 1521 ................... & 0 & $1540 \ldots \ldots \ldots \ldots \ldots \ldots$ & 11 \\
\hline & $1522 \ldots \ldots \ldots \ldots \ldots \ldots \ldots \ldots \ldots$ & 4 & $1541 \ldots \ldots \ldots \ldots \ldots \ldots$ & 2 \\
\hline & $1523 \ldots \ldots \ldots \ldots \ldots \ldots \ldots$ & 0 & $1542 \ldots \ldots \ldots \ldots \ldots \ldots$ & 3 \\
\hline & $1524 \ldots \ldots \ldots \ldots \ldots \ldots \ldots \ldots$ & 4 & $1543 \ldots \ldots \ldots \ldots \ldots \ldots$ & 3 \\
\hline & $1525 \ldots \ldots \ldots \ldots \ldots \ldots \ldots \ldots$ & 6 & $1544 \ldots \ldots \ldots \ldots \ldots \ldots$ & 1 \\
\hline & $1526 \ldots \ldots \ldots \ldots \ldots \ldots$ & 2 & 1545 ...................... & 17 \\
\hline & $1527 \ldots \ldots \ldots \ldots \ldots \ldots$ & 4 & $1546 \ldots \ldots \ldots \ldots \ldots \ldots$ & 5 \\
\hline - & $1528 \ldots \ldots \ldots \ldots \ldots \ldots . . . . . .$. & 3 & 1547 ................. & 4 \\
\hline & 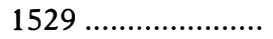 & 2 & $1548 \ldots \ldots \ldots \ldots \ldots \ldots$ & 17 \\
\hline & 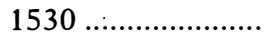 & 3 & 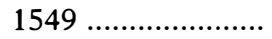 & 12 \\
\hline & $1531 \ldots \ldots \ldots \ldots \ldots \ldots$ & 3. & $1550 \ldots \ldots \ldots \ldots \ldots \ldots$ & 9 \\
\hline & $1532 \ldots \ldots \ldots \ldots \ldots \ldots$ & 8 & $1551 \ldots \ldots \ldots \ldots \ldots \ldots$ & 9 \\
\hline & $1533 \ldots \ldots \ldots \ldots \ldots \ldots$ & 5 & $1552 \ldots \ldots \ldots \ldots \ldots \ldots$ & 2 \\
\hline & 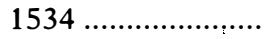 & 5 & $1553 \ldots \ldots \ldots \ldots \ldots \ldots$ & 7 \\
\hline & $1535 \ldots \ldots \ldots \ldots \ldots \ldots \ldots$ & 0 & $1554 \ldots \ldots \ldots \ldots \ldots \ldots$ & 2 \\
\hline & 1536 .................. & 6 & 1555 ................... & 5 \\
\hline & $1537 \ldots \ldots \ldots \ldots \ldots \ldots \ldots \ldots \ldots$ & 6 & $1556 \ldots \ldots \ldots \ldots \ldots \ldots$ & 6 \\
\hline & $1538 \ldots \ldots \ldots \ldots \ldots \ldots$ & 7 & 1557 .................. & 3 \\
\hline & $1539 \ldots \ldots \ldots \ldots \ldots \ldots \ldots$ & 6 & & \\
\hline & TOTAI & & 193 & \\
\hline
\end{tabular}


de exame era semelhante ao dos seus congéneres castelhanos, ou seja, mediante a aprovação do examinador, o físico-mor ou o cirurgião-mor, e tal como para os fisicos e cirurgiões portugueses (55). De qualquer modo, os pormenores do exame são-nos desconhecidos, uma vez que as 193 cartas analisadas são omissas a esse respeito.

Quanto aos examinadores, aparecem os nomes do fisico-mor Dr. Diogo Lopes, até 1543, e de Mestre Lopo, boticário de D. João III, nos anos de 1525 e 1526, em parelelo com outras cartas cujo examinador foi o referido físico-mor. A partir de 1544 temos o nome do Dr. Diogo Franco, se bem que muitas cartas das décadas de 40 e 50 apenas refiram o Dr. Mestre Diogo. A partir de 1551 continuam a parecer cartas do mesmo, bem como do físico-mor, o licenciado Leonardo Nunes.

A variação das cartas, ao longo do período em estudo, é bastante irregular, oscilando entre nenhuma nos anos de 1521 - de facto, o reinado de D. João III apenas abrange alguns dias de Dezembro deste ano-, 1523,1535 , para atingir $17 \mathrm{em} 1545$ e em 1548. A média é de cirico cartas por ano. Contudo, a década de 40 foi a mais importante, com 73 documentos, ou seja, $38 \%$ do total.

Igualmente a distribuilção geográfica dos boticários ao longo do reino está longe de ser equitativa. Por ordem decrescente temos as comarcas da Estremadura - com 53 boticários em Lisboa, 11 em Santarém, quatro em Coimbra e um em Aveiro, Oeiras, Óbidos, Benavente, Leiria, Tomar, Almeirim, Torres Novas, Caldas e Alenquer -Além Tejo-com cartas outorgadas a 13 boticários de Évora, sete de Setúbal, cinco de Montemor-o Novo, três de Alcacer e de Beja, dois de Serpa, de Moura de Portalegre e de Olivença, e um do Crato, de Avis, de Portel, de Elvas, de Viana a par de Alvito, de Torrão, de Campo Maior, de Estremoz, de Vila Viçosa, de Sesimbra e de Castelo de Vide -Algarve- nomeadamente com oito boticários de Tavira, três de Faro e um de Portimão - Beiracom seis em Lamego, dois na Covilhã, e um na Guarda, e outro em Viseu - Entre Douro e Minho- comarca da qual recebem carta de boticário dois indivíduos do Porto, dois de Viana e um de Braga e por último Trásos-Montes com dois em Miranda do Douro, um em Vila Real e outro em Vila Flor.

Nos arquipélagos da Madeira e dos Açores, bem como nas zonas de presença portuguesa do continente africano e da Ásia existiam igualmente boticários portugueses. Na Madeira estava Diogo Romeiro, cuja carta data de 1525 (56) e Luís Meireles, o qual obteve licença em 1550 (57). Antes ainda, em 1528, Miguel Antunes, estante no Funchal (58), tal como Al- 
varo de Meireles, em 1531 (59), também obtiveram cartas. Em 1545, foi a vez de Inhego Lopes, morador em Santa Cruz (60) e em 1548 a de Rui Gonçalves, da Calheta (61). Nos Açores temos Henrique Coronel, da ilha Terceira, cuja carta é de 1549 (62) e António Rodrigues, de Ponta Delgada, de 1551 (63).

Para Arzila irá Aires Vaz a partir de 1546 (64), substituindo o pai, Rui Vaz, e tendo 4000 reais de tença por ano, depois de ter obtido carta de boticário em 1545 (65). Em 1534, Francisco de Colhera, morador em Alcácer Ceguer, fica aí como boticário, após o exame de Diogo Lopes, substituindo Diogo de Colhera, seu pai, então falecido (66). Afonso Cide irá para S Jorge da Mina em 1546 (67), Duarte da Costa em 1551 (68) e André Filipe no ano seguinte (69). Em 1553 será a vez de António Fernandes (70), enquanto Cristóvão Vaz obterá carta em 1555, depois de ser boticário na Mina durante dois anos (71).

No Oriente, concretamente em Goa, foram boticários Salvador Gonçalves, com carta de 1532 (72) e Fernão Rodrigues, com documento semelhante obtido em 1541 (73). Por seu turno, em 1538, João Rodrigues, morador em Goa, foi provido pelo governador da India para ir desempenhar tal ofício em Diu (74). Em Ormuz, Gaspar Gonçalves detinha a botica do hospital desde 1540 (75), havendo ainda a registar os nomes de António Mendes (76) e de Francisco Lopes, este com cargo só por três anos (77), e ainda o de Álvaro Pinto, nomeado em 1550 (78). Alguns documentos fornecem mais informações sobre as actividades destes e de outros boticários (79). Por exemplo, Simão Alvares, boticário em Maluco, recebeu do feitor 12032 reais em 1530 (80). Bernardo Pires, boticário em Baçaim, deveria fornecer as mezinhas a o hospital local, segundo informa um documento de 1539 (81). Em 1550, o boticário de Goa entregou aos hospitais de Cochim muitas mezinhas que constam dum rol - de entre os produtos temos emplastros, xaropes, óleos, pós, canafistola, unguentos, ruibarbo, cana de mirabolano, água rosada, mirra, vinagre rosado, tamarindo, coral, incenso, cera, farinha, especiarias, pedra ume, mel rosado, canfora, açúcar rosado, ovos, sumos, sementes e gomas de «toda a sorte» (82). Em Chaul o boticário do hospital era, em 1528, Bartolomeu Gonçalves, solvendo o ordenado de 30 mil reais por ano, e, em 1545, estava como boticário mor Simão Álvares (83).

Os serviços dos boticários eram, por vezes, recompensados com mercês. Em 1532 Pero Fernandes, boticário em Tanger, passou a receber 4000 reais por ano, enquanto aí mantivesse a botica «de comtyno provida de todas as mezinhas e cousas necessaryas pera os doentes e ferydos que 
na dita cydade ha» (84). Em 1542 João Rodrigues, boticário em Diu, foi feito cavaleiro por ter participado no socorro do cerco de Diu com António da Silveira (85). Outros documentos fornecem-nos informações diferentes. Por um de 1535 sabemos que Mestre Lopo, boticário do rei, recebeu 2736 reais de vestiaria (86). Em 1542 aposentar-se-á. Passará a receber, a partir de 1543, uma tença anual, até à sua morte, de três moios de trigo assentados no almoxarifado do reguengo novo de Beja (87). Em 1549, como cavaleiro da casa do rei, passou a receber a tença de $18 \mathrm{mil}$ reais, 13.522 de moradia e o resto de vestiaria, tudo em numerário (88). Em Agosto de 1554 tinha já falecido. Foi então nomeado Diogo Romeiro de Aramaio, o qual passou a receber 365 reais por mês e três quartos de cevada por dia quando tivesse cavalo, além de outras regalias (89). Estas determinações devem ter substituído umas outras anteriores, que Ihe concediam 20 mil reais por ano (90). Anos antes, em 1534, era boticário do rei um Tristão de Azevedo, o qual recebeu 2736 reais de vestiaria (91).

A Rainha D. Catarina também recompensou os seus boticários. Em 1527 servia-a Mateus Moreno, o qual recebeu 20 mil reais de mercê. Em 1530 recebeu serviços de João Nunes e a partir de 1550 de Luís Nunes (92). Por seu turno, João Rodrigues de Sequeira serviu na botica da infanta D. Maria, vindo a ser contemplado com 10 mil reais de tença por ano. A infante teve também ao serviço da sua botica Duarte Ribeiro, que recebeu igual quantia (93).

A importância dos boticários era grande. Como profissionais da saúde parecem ter sido bem vistos, quer pela coroa, quer pelas populações em geral. A sua preparação supervisionada pelo físico-mor ou pelo boticário do rei, os quais só passavam cartas de boticários áqueles que «avia muitos anos [...] que usava e praticava arte de botica» (94), ou aos que o examinador encontrava "asy idonyo e expreto e soficiemte» (95), constituíam uma garantia da qualidade dos serviços prestados por estes homens. Nem todas as terras possuíam botica e boticários. A sua concentração nos centros urbanos, não impediu, contudo, que locais mais pequenos tivessem oportunidade de beneficiar dos serviços destes agentes de saúde. Por vezes, são as próprias terras que os solicitam à coroa, tal como Serpa em 1557 (96).

Mesmo assim, nem tudo corria bem aos boticários. Uns tiveram problemas com a Inquisição (97); outros foram vítimas dos roubos dos Franceses, tal é o caso de Afonso Rodrigues, morador em Tavira, que no ano de 1536 ficou sem uma carga de figos (98); outros ainda, como Fernando Rodrigues, boticário em Goa, teve um dissídio com os irmãos da Misericór- 
dia local sobre o preço das mezinhas (99). Problemas de índole diferente foram sentidos por Salvador Gonçalves, morador em Lisboa, o qual solicitou em 1526 licença de porte de armas, depois de ter sido demandado por Francisco Rodrigues, que o acusou de ter dormido com a filha (100); ou ainda Jerónimo Rodrigues, igualmente boticário em Lisboa, que requereu licença semelhante em 1539, porque receava Diogo Fernandes, um serralheiro que já o havia feriḍo na mão e o ameaçara de morte (101).

Sobre a influência social deste grupo e o seu poder económico pouco sabemos. Alguns parecem ter tido uma situação estável (102). Vários obtiveram licença para andar de mula - tais são os casos de Gonçalo Fernandes, morador em Évora (103), Mestre Lopo, este já com licẹnça de D. Manuel, confirmada em 1528 por D. João III (104); bem como, em 1523, Francisco Gonçalves, igualmente boticário do rei (105) e Pedro Dias, morador em Montemor-o-Novo (106). Outros ainda, como António Rodrigues, boticário em Tomar, conseguiram carta de privilégio de cidadão do Porto (107).

Os boticários aparecem ainda envolvidos em negócios diversos. Não só ligados às mezinhas, como nos demonstram os documentos referentes às receitas e remédios que se deram aos doentes da armada do Estreito em 1528 (108), ou aos medicamentos fornecidos às galeotas em 1531 (109), ou ao hospital de Évora um ano antes (110), ou ainda aos fármacos para as boticas com destino a Safim, à Mina e à armada do Levante (111). Mas também em relação ao aforamento de duas boticas à porta da Alfama, em Lisboa, como o fez Tristão da Cunha, fidalgo da casa do rei, em 1540 (112), bem como a compra, por Sebastião Vaz, boticário de Évora, de 144 reais de foro de umas casas à Porta Nova por 4320 reais. As casas eram foreiras do rei, o qual mandou vender os foros à razão de $30 \mathrm{mil}$ reais o milheiro (113).

Havia ainda homens que começavam por ser boticários, ou pelo menos dominar o conhecimento das ervas, obtendo mais tarde cartas de físicos e de cirurgiões. Em 1540 Filipe Ferreira, morador em Alcochete «com algumas mezinhas scilicet ervas e raizes sabia curar de muitas enfermidades», vindo a conseguir autorização para o exercício de «curar de físico» em Alcochete e Ribatejo (114) João Teixeira, boticário, morador em Leiria, obteve, em 1551, carta de cirurgia, após ter sido examinado pelo Doutor Mestre Gil, cirurgião-mor (115).

No cerimonial das procissões, nomeadamente da de Corpus Christi, sabe-se que, desde 1518, os mercadores dos panos de Santarém precediam os boticários havendo a seguinte ordem: quatro tochas da câmara no iní- 
cio, duas dos tabeliães do judicial, duas dos tabeliães das notas, quatro dos mercadores e duas dos boticários. Tal foi confirmado em 1535 (116).

Temos assim um conjunto de elementos que nos permitem fazer alguma ideia da importância dos boticários portugueses durante o reinado de D. João III, quer no reino, quer nos territórios de presença portuguesa em África e na Ásia. Se bem que o número deles seja obviamente maior do que aqueles que obtiveram carta neste período - basta pensarmos nos que vieram do reinado de $\mathrm{D}$ Manuel — a documentação estudada permite tecer algumas considerações que visaram explicitar melhor o papel destes profissonais da saúde pública deste período. 
ANEXO I

BOTICÁRIOS DE PORTUGAL CONTINENTAL EXAMINADOS ENTRE 1522 E 1557

\begin{tabular}{|c|c|c|c|}
\hline Fonte a) & Data & Nome & Local \\
\hline liv. 51 , fol. 11 & $7-2-1522$ & Gabriel Tavares & Lisboa \\
\hline liv. 51 , fol. $138 v$ & $5-3-1522$ & Gonçalo Fernandes & Santarém \\
\hline liv. 51 , fol. $182 v$ & $25-6-1522$ & Jorge de Morais & Lisboa \\
\hline liv. 46 , fol. 111 & 9-7-1522 & Francisco de Aragão & Lisboa \\
\hline liv. 41 , fol. 84 & $26-2-1524$ & Francisco Pires & Olivença \\
\hline liv. 37 , fol. $21 \mathrm{v}$ & $5-4-1524$ & Pero Francisco & Lisboa \\
\hline liv. 37 , fol. 68 & $14-5-1524$ & Manuel Nunes & Coimbra \\
\hline liv. 37, fol. $93 \mathrm{v}$ & $24-6-1524$ & Diogode Pais & Portalegre \\
\hline liv. 8 , fol. $43 v$ & $1-3-1525$ & Belchior Fernandes & Évora \\
\hline liv. 8 , fol. $44 v$ & $12-3-1525$ & Francisco Mendes & Évora \\
\hline liv. 36 , fol. $72 v$ & $6-5-1525$ & Domingos Alvares & Beja \\
\hline liv. 8 , fol. $137 \mathrm{v}$ & $10-6-1525$ & Silvestre Lourenco & Santarém \\
\hline liv. 8 , fol. 138 & $28-11-1525$ & Afonso Fernandes & Tavira \\
\hline liv. 36 , fol. 26 & $30-1-1526$ & João Penteado & Setúbal \\
\hline liv. 36 , fol. $89 v$ & $2-6-1526$ & Diogo Nunes & Beja \\
\hline liv. 36, fol. 155 & $8-8-1526$ & António Filipe & Lisboa \\
\hline liv. 30 , fol. $118 v$ & $27-2-1527$ & Afonso Lopes & Lisboa \\
\hline liv. 30 , fol. 78 & $22-3-1527$ & António Coresma & Tavira \\
\hline liv. 30 , fol. $116 \mathrm{v}$ & $30-7-1527$ & Pedro Dias & Portel \\
\hline liv. 30, fol. 170 & $12-10-1527$ & Manuel Vaz & Faro \\
\hline liv. 14 , fol. $20 \mathrm{v}$ & $2-2-1528$ & Femão Vaz & Moura \\
\hline liv. 47 , fol. 38 & $14-5-1529$ & Garaa de Gusmão & Tavira \\
\hline liv. 14 , fol. 108 & $26-5-1528$ & João Ferreira & Setúbal \\
\hline liv. 48 , fol. 58 & 8-8-1529 & Femão Dias & Lisboa \\
\hline liv. 19, fol. 179 & 29-1-1530 & Jorge Calado & Lisboa \\
\hline liv. 42 , fol. $39 v$ & 4-3-1530 & Estevão Nunes & Lisboa \\
\hline liv. 9 , fol. 53 & $18-12-1530$ & Manuel Hennques & Lisboa \\
\hline liv. 9, fol. 31 & $10-3-1531$ & Manuel Pires & Beja \\
\hline liv. 9, fol. 58 & $30-6-1531$ & Simão Rodrigues & Santarém \\
\hline liv. 16, fol. 37 & $11-4-1532$ & DiogoVaz & Lisboa \\
\hline liv. 16 , fol. $42 v$ & $16-4-1532$ & Jorge Pinheiro & Montemor-o-Novo \\
\hline liv. 16 fol. $52 \mathrm{v}$ & $10-5-1532$ & Francisco Rodrigues & Lisboa \\
\hline liv. 16. n 112 & 7-8-1532 & João Dias & Lisboa \\
\hline liv. 16 fol. $125 \mathrm{v}$ & 24-9-1532 & João Fernandes & Aveiro \\
\hline liv. 19 , fol. $209 \mathrm{v}$ & $13-10-1532$ & Luís Fernandes & Lisboa \\
\hline liv. 19, fol. 98 & $2-12-1532$ & Pedro Fernandes & Lisboa \\
\hline liv. 19 , fol. 17 & 19-1-1533 & Jerónimo Rodrigues & Portalegre \\
\hline
\end{tabular}

Asclepio-Vol. XLVI-2-1994 


\begin{tabular}{|c|c|c|c|}
\hline Fonte a) & Data & Nome & Local \\
\hline liv. 19 , fol. $28 \mathrm{v}$ & $31-1-1533$ & Álvaro Lourenço & Tavira \\
\hline liv. 19 , fol. $58 \mathrm{v}$ & $8-3-1533$ & Pedro Teixeira & Lisboa \\
\hline liv 19, fol. 118 & $8-6-1533$ & Manuel Álvares & Lisboa \\
\hline liv. 19 , fol. 138 & $5-8-1533$ & Jorge Duarte & Porto \\
\hline liv. 7, fol. 23v & $28-1-1534$ & Rui Lopes & Santarém \\
\hline liv. 7 , fol. $68 v$ & $24-3-1534$ & Sebastião Vaz & Évora \\
\hline liv. $7,171 \mathrm{v}$ & 4-9-1534 & Jorge Gomes & Évora \\
\hline liv. 7, fol. 171 & $8-9-1534$ & Álvaro Nunes & Santarem \\
\hline liv. 21 , fol. 15 & $27-1-1536$ & Simão Gomes & Évora \\
\hline liv. 5 , fol. 120 & $8-8-1536$ & Simão Pinto & Viana \\
\hline liv. 22, fol. 95 & $8-10-1536$ & António Gitar & Lisboa \\
\hline liv. 21 , fol. 182 & $10-10-1536$ & Manuel Dias & Montemor-o-Novo \\
\hline liv. 21 , fol. 206 & $23-11-1536$ & Francisco Galindo & Évora \\
\hline liv. 24 , fol. 25 & 28-1-1537 & Francisco Femandes & Évora \\
\hline liv. 24 , fol. 20 & 28-1-1537 & Pedro de Gouveia & Lamego \\
\hline liv. 24 , fol. 67 & $12-3-1537$ & Diogo Mendes & Évora \\
\hline liv. 24, fol. 209vi & $18-9-1537$ & João Delgado & Lisboa \\
\hline livc. 49 , fol. $138 \mathrm{v}$ & $15-11-1537$ & Estevão Dias & Lisboa \\
\hline liv. 39, fol. 7 & . 4-12-1537 & Mem Martins & Lisboa \\
\hline liv. 49 , fol. $59 \mathrm{v}$ & $29-3-1538$ & Francisco Mourão & Covilhã \\
\hline liv. 49 , fol. 73 & $19-4-1538$ & António de Barentos & Guarda \\
\hline liv. 49, fol. 107 & $23-5-1538$ & Manuel Dias & Coimbra \\
\hline liv. 49 , fol. 143 & $19-6-1538$ & Nuno Martins & Alcácer \\
\hline liv. 49, fol. 153 & $12-7-1538$ & Manuel Álvares & Lamego \\
\hline liv. 49 , fol. $261 \mathrm{v}$ & $23-11-1538$ & Antão Gonçalves & Santarém \\
\hline liv. 26, fol. 74v & . 15-3-1539 & Gregório Fernandes & Lisboa \\
\hline liv. 26, fol. 121 & 24-5-1539 & Rui Dias & Lamego \\
\hline liv. 26, fol. 168 & 2-8-1539 & Afonso Cide & Santarém \\
\hline liv. 26 , fol. $182 v$ & $21-8-1539$ & António Gomes & Tavira \\
\hline liv. 26 , fol. 220 & $4-10-1539$ & Gaspar Gonçalves & Lisboa \\
\hline liv. 26 , fol. $238 v$ & 3-11-1539 & Henrique Godinho & Alcácer \\
\hline liv. 40 , fol. 4 & $7-1-1540$ & Tomạs Álvares & Oeiras \\
\hline liv. 40 , fol. 30 & $16-2-1540$ & Francisco de Baeça & Portimão \\
\hline liv. 40, fol. 96 & $7-5-1540$ & Manuel Rodrigues & Setúbal \\
\hline liv. 40 , fol. $110 \mathrm{v}$. & $1 \cdot 2-5-1540$ & Fernão de Góis & Lisboa \\
\hline liv. 40, fol. $111 \mathrm{v}$ & $2-9-1540$ & Luís de Pina & Elvas \\
\hline liv. 40 , fol. $158 \mathrm{v}$ & $29-7-1540$ & Francisco Verga & Lisboa \\
\hline liv. 40, fol. 160 & $30-7-1540$ & Heitor Lopes & Évora \\
\hline liv. 40, fol. 191v & $2-9-1540$ & Jorge Nogueira & Lisboa \\
\hline liv. 40, fol. 199 & $28-9-1540$ & Baltasar Lopes & Lisboa \\
\hline liv. 40 , fol. $217 \mathrm{v}$ & $15-10-1540$ & Sebastião Mendes & Miranda do Douro \\
\hline liv. 31 , fol. $9 v$ & 5-2-1541 & Alvaro Marques Vadilho & Obidos \\
\hline liv. 38 , fol. 128 & $5-9-1542$ & João Ribeiro & Setúbal \\
\hline
\end{tabular}




\begin{tabular}{|c|c|c|c|}
\hline Fonte a) & Data & Nome & Local \\
\hline liv. 38 , fol. 169 & $27-9-1542$ & António Lopes & Lisboa \\
\hline liv. 6 , fol. 38 & $9-2-1543$ & Jacome Rodrigues & Lamego \\
\hline liv. 6 , fol. 62 & $9-4-1543$ & Miguel Femandes & Benavente \\
\hline liv. 6 , fol. 116 & $21-8-1543$ & Simão Lopes & Leina \\
\hline liv. 5 , fol. $142 v$ & $6-12-1544$ & Simão Pires & Évora \\
\hline liv. 25 , fol. 156 & $23-10-1545$ & Bento Rodrigues & Lisboa \\
\hline liv. 25 , fol. $66 \mathrm{v}$ & $13-4-1545$ & Fernão de Morais & Covilhã \\
\hline liv. 25 , fol. 64 & $13-4-1545$ & Manuel Gomes & Évora \\
\hline liv. 25 , fol. 76 & $20-4-1545$ & João Femandes & Coimbra (b) \\
\hline liv. 25 , fol. 106 & $16-6-1545$ & Diogo Rodrigues & Évora \\
\hline liv. 25 , fol. 105 & $16-6-1545$ & Pero Taborda & Tomar \\
\hline liv. 25 , fol. $128^{\circ}$ & $20-7-1545$ & Jorge Dinis & Lisboa \\
\hline liv. 25 , fol. 166 & $29-9-1545$ & Vasco Baião & Tavira \\
\hline liv. 25 , fol. $170 \mathrm{v}$ & $4-10-1545$ & Miguel Rodrigues & Faro \\
\hline liv. 25, fol. 175 & $7-10-1545$ & Bento Lopes & Montemor-o-Novo \\
\hline liv. 25, fol. 180 & $16-10-1545$ & Diogo Martins & Torrão \\
\hline liv. 25 , fol. $180 \mathrm{v}$ & $22-10-1454$ & Fernão Gomes & Montemor-o-Novo \\
\hline liv. 25 , fol. 181 & $23-10-1545$ & Jorge Cardoso & Lamego \\
\hline liv. 25, fol. 184 & 3-11-1545 & Pedro Rodrigues & Olivença \\
\hline liv. 25 , fol. $195 v$ & $8-11-1545$ & Luís Mendes & Moura \\
\hline liv. 33 , fol. 8 & $21-1-1546$ & Manuel Varela & Almeirim \\
\hline liv. 33 , fol. $8 v$ & $23-1-1546$ & António Sardinha & Santarém \\
\hline liv. 33 , fol. $8 v$ & $4-2-1546$ & Francisco Dias & Lisboa \\
\hline liv. 15 , fol. 102 & $2-8-1547$ & João Rabelo & Lisboa \\
\hline ív 38, fol. 128 & $5-9-1547$ & João Ribeiro & Setúbal \\
\hline liv. 38, fol. 169 & $27-9-1547$ & António Lopes & Lisboa \\
\hline liv. 70, fol. 112v & $28-1-1548$ & Diogo de Castro & Lisboa \\
\hline liv. 55 , fol. $25 v$ & $14-2-1548$ & Afonso de Ilhoa & Lisboa \\
\hline liv. 60 , fol. $10 \mathrm{v}$ & $14-2-1548$ & Francisco Lopes & Lisboa \\
\hline liv. 67, fol. 14 & $13-3-1548$ & João Vaz & Faro \\
\hline liv. 70, fol. 23 & $30-3-1548$ & Simão Nunes & Lisboa \\
\hline liv. 67 , fol. $22 \mathrm{v}$ & $21-4-1548$ & Estêvão Dias & Setúbal \\
\hline liv. 60 , fol. 62 & $6-5-1548$ & Manuel Ferreira & Lisboa \\
\hline liv. 67 , fol. $45 v$ & $13-3-1548$ & Duarte Ribeiro & Torres Novas \\
\hline liv. 67, fol. 67 & 284-1548 & Francisco Sanches & CampoMaior \\
\hline liv. 70, fol. 82 & $25-10-1548$ & António Femandes & Lisboa \\
\hline liv. 67 , fol. $98 v$ & $28-10-1548$ & Lopo Nunes & Montemor-o-Novo \\
\hline liv. 67, fol. 100 & $13-11-1548$ & Jorge Botelho & Viana (Alvito) \\
\hline liv. 67, fol. 105v & $23-12-1548$ & Duarte Mendes & Estremoz \\
\hline liv. 70 , fol. $112 \mathrm{v}$ & 28-1-1549 & Diogo de Castro & Lisboa \\
\hline liv. 55, fol. 164 & $22-7-1549$ & Sebastião Nunes & Vila Viçosa \\
\hline liv. 70 , fol. $172 \mathrm{v}$ & $25-7-1549$ & Sebastião de Vila Fanha & Porto \\
\hline liv. 70, fol. 180 & $30-7-1549$ & Francisco Gomes & Lisboa \\
\hline
\end{tabular}

Asclepio-Vol. XLVI-2-1994 


\begin{tabular}{|c|c|c|c|}
\hline Fonte a) & Data & Nome & Local \\
\hline liv. 60 , fol. $151 \mathrm{v}$ & $7-9-1549$ & Francisco Barbudo & Lisboa \\
\hline liv. 55, fol. 197 & $16-9-1549$ & Álvaro de Solis & Lisboa \\
\hline liv. 70 , fol. $217 \mathrm{v}$ & $10-10-1549$ & Heitor de Matos & Sesimbra \\
\hline liv. 62 , fol. 37 & $28-3-1550$ & Pero de Morais & Caldas \\
\hline liv. 62. fol. 59v & $22-5-1550$ & Gabriel Manins & Tavira \\
\hline liv. 66 , fol. 62 & $28-5-1550$ & Duarte da Costa & Lisboa \\
\hline liv. 64 , fol. 102 & $27-7-1550$ & João da Costa & Miranda \\
\hline liv. 64 , fol. 107 & $28-7-1550$ & Jerónimo Fernandes & Santarém \\
\hline liv. 64 , fol. 119 & $26-9-1550$ & Simão Luís & Castelo de Vide \\
\hline liv. 64 , fol. 144 & $12-10-1550$ & Pedro Nunes & Alcácer \\
\hline liv. 60 , fol. $185 \mathrm{v}$ & $4-12-1551$ & Duarte da Costa & Lisboa \\
\hline liv. 71, fol. 110v & 1-8-1551 & Diogo Nunes & Lisboa \\
\hline liv. 62 , fol. $265 \mathrm{v}$ & $26-10-1551$ & Henrique Nunes & Viseu \\
\hline liv. 62 , fol. $276 \mathrm{v}$ & $20-11-1551$ & João Cardoso & Lamego \\
\hline liv. 62 , fol. $278 v$ & $3-12-1551$ & Gabriel Pinto & Coimbra \\
\hline liv. 62 , fol. 277 & $4-12-1551$ & António Esteves & Vila Real \\
\hline liv. 56 , fol. 94v & $307-1552$ & Álvaro Mendes & Lisboa \\
\hline liv. 56, fol. 199 & $26-2-1553$ & Álvaro Martins & Setúbal \\
\hline liv. 56, fol. 252 & $11-8-1553$ & Francisco Quaresma & Serpa \\
\hline $\operatorname{liv} 68$, fol. 296v & $22-10-1553$ & António Femandes & Lisboa \\
\hline liv. 68 fol. 315v & $6-12-1553$ & Pedro Garcia & Alenquer \\
\hline liv. 56, fol. 156 & $27-1-1553$ & Heitor Rodrigues & Braga \\
\hline liv. 57. fol. 125 & $12-11-1554$ & Gonçalo Rodrigues & Tavira \\
\hline liv. 63 , fol. $146 \mathrm{v}$ & 23-11-1554 & Gonçalo Barasa & Crato \\
\hline liv. 62 , fol. 5 & 8-1-1555 & Alvaro Goteres & Lisboa \\
\hline liv. 63, fol. 209 & $4-3-1555$ & João Dias Cide & Santarém \\
\hline liv. 63 fol. $222 \mathrm{v}$ & $12-3-1555$ & Rui Gomes & Lisboa \\
\hline liv. 57, fol. 218 & $15-3-1555$ & Francisco Lopes & Lisboa \\
\hline liv. 54 fol. $10 \mathrm{v}$ & $28-1-1556$ & António Luís & Viana \\
\hline liv. 54 , fol. $23 v$ & $7-3-1556$ & Jorge Vaz & Évora \\
\hline $\operatorname{liv} 71$, fol. $110 \mathrm{v}$ & $1-8-1556$ & Diogo Nunes & Lisboa \\
\hline liv. 65 , fol. $148 v$ & $7-10-1556$ & Diogo Pires Nogueira & Santarém \\
\hline liv. 65 fol. 161 & $18-11-1556$ & Bento Rodrigues & Lisboa \\
\hline liv. 54 fol. $340 \mathrm{v}$ & $25-6-1557$ & Francisco Quaresma & Serpa \\
\hline liv. 59, fol.80 & $26-6-1557$ & Pero Lopes Marcos & Vila Flor \\
\hline liv. 65 , fol. 310 & $30-7-1557$ & Alvaro Lopes & Avis \\
\hline
\end{tabular}

a) Arquivos Nacionais/Tombo do Tombo, Chancelaria de D. João III.

b) João Femades já era boticário. Nesta data passa a sê-lo na universidade. 


\section{NOTAS}

(1) Maria José Pimenta Ferro Tavares (1989), Pobreza e Morte em Portugal na Idade Média, Lisboa, Presença, 124-145; Maria Helena DA CRUz CoElho (1990), «A Acção dos Particulares para com a Pobreza nos Séculos XI e XII", in Homens, Espaços e Poderes, Séculos XI-XVI, vol. I (Notas do Viver Social), Lisboa, Horizonte, pp. 78-101; Hermínia DE Vasconcelos Vilar (1990), Vivência da Morte na Estremadura Portuguesa, 1330-1550, vol. 1, Lisboa, Dissertação de Mestrado em História Medieval apresentada à Faculdade de Ciências Sociais e Humanas da Universidade Nova de Lisboa.

(2) Maria José Ferro Tavares, Op. cit., pp. 124-245; Maria Helena Coelho, op. cit., pp. 78-101.

(3) Paulo Drumond Braga (1991), «A Crise dos Estabelecimentos de Assistência aos Pobres nos finais da Idade Média», Revista Portuguesa de História, tomo XXVI, Coimbra, pp. $175-190$.

(4) Joaquim Veríssimo Serrāo (1980), História de Portugal, vol. 3, Lisboa, p. 356.

(5) Maria José Pimenta Ferro Tavares (1987), «A Política Municipal de Saúde Pública (Séculos XIV-XV)», Revista de História Económica e Social, vol. 19, Lisboa, pp. 17-32.

(6) Sobre a geografia da peste no século XVI cfr. Isabel M R. MENDEs DRUMOND BRAGA, «Para o Estudo do Medo no Portugal Quinhentista: Peste e Religiosidade», Revista de Ciências Históricas, no prelo.

(7) Isabel M. R. Mendes Drumond BraGa (1994), "Contribuição Monetária das Comarcas Portuguesas para a Obra da Redenção de Cativos (1523-1539)», Brigantia, vol. 14, Bragança, pp. 23-34.

(8) Sobre a cobertura hospitalar do País na época de D. João III cf. Veríssimo SERRÃO, op. cit., pp. 356-357.

(9) Francisco Bethencourt (1987), O Imaginário da Magia, Feiticeiras, Sa/udadores e Nigromantes no SéculoxvI, Lisboa, Universidade Aberta, pp. 51-66. boa.

(10) Joaquim Veríssimo Serrāo (1971), Portugueses no Estudo de Salamanca. Lis-

(11) Joaquim Veríssimo SERRÃo (1971), Les Portugais à l'Université de Montpellier, Paris.

(12) Joaquim Veríssimo SERRĀo, História de Portugal, [...], vol. 3, p. 356.

(13) Joaquim Veríssimo Serrāo (1983), História das Universidades, Porto, Lello \& Irmão, p. 109.

(14) Maximiano De Lemos (1991), História da Medicina em Portugal. Doutrinas e Instituições, vol. 1, Lisboa; p. 146.

(15) Idem, Ibidem, pp.147-148.

(16) Idem (1886), «Medicina Portuguesa. O Hospital Real de Todos os Santos», $A$ Medicina Contemporanea, n. ${ }^{\circ} 33$, Lisboa, p. 76; Nicolás Pérez Jiménez (1875), Escuela de Medicina del Monasterio de Guadalupe, Badajoz, p. 63.

(17) Guy Beaujouan (1966), Médecine Humaine ou Véterinaire à la Fin du Moyen Âge, Paris, , p. 382. Sobre a cirurgia cf. Nancy G. SiRAISI (1990), Medieval and Early Renaissance Medecine. An Introduction to Knowledge and Practice, Chicago, Londres, pp.153-186.

Asclepio-Vol. XLVI-2-1994 
(18) Isabel Maria RiBeiro Mendes (1991), "Portugueses na Inquisição de Toledo: o Processo de Manuel Gomes da Silveira (1631-1632), Médico em Guadalupe», Portugaliae Historica, II série, vol. I, Lisboa, pp. 259-278.

(19) Idem, Ibidem, p. 268-269.

(20). Arquivos Nacionais / Torre do Tombo, Chancelaria de D. João III, Perdões e Legitimações, liv. 28, fols. 87v-88.

- (21) A.N./T.T., Chancelaria de D. João III, Oficios. Padrões e Doações, liv. 5, fol. 34v.

(22) A.N./T.T., Chancelaria de D. João III, Oficios. Padrões e Doações, liv. 5, fol. 69.

(23) A.N./T.T., Chancelaria de D. João III, Oficios, Padrões e Doações, liv. 6, fol. 143v.

(24) A.N./T.T., Chancelaria de D. João III, Oficios, Padrões e Doações, liv. 56, fol. $104 \mathrm{v}$.

(25) Para a época medieval cf. Iria Gonçalves (1988), «Físicos e Cirurgiões Quatrocentisas. As Cartas de Exame», Imagens do Mundo Medieval, Lisboa, Horizonte, pp- 9-52.

(26) A.N./T.T., Chancelaria de D. João III, Oficios, Padrões e Doações, liv. 16, fols. 64 $64 v$.

(27) José Mattoso (1984), «Saúde Corporal e Saúde Mental na Idade Média Portuguesa", Fragmentos de uma Composição Medieval, Lisboa, Estampa, pp. 233-259.

(28) Iria GonçAlves, op. cit., pp. 9-52.

(29) Mário da Costa Roque (1984), "Cirurgiões, Boticários, Parteiras e Barbeiros que na sua maior parte viveram em Lisboa nos séculos XVI e XVII", Anais da Academia

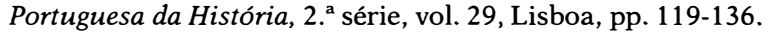

(30) Maximiano DE LEMos, op. cit., vol. 1, p. 95.

(31) Félix Francisco Pastor Frechoso (1993), Boticas, Boticarios y Materia Medica en Valladolid (Siglos XVI y XVII), [s.l.], pp. 25-26.

(32) Maximiano DE LEMOS, op. cit., p. 96.

(33) Manuel das Dores Tello da Fonseca (1941), História da Farmácia Portuguesa através da sua Legislação, vol. 3, Porto, pp. 5-10.

(34) Idem, Ibidem, p. 11.

(35) Maximiano de Lemos, op. cit., pp. 96-97.

(36) José Leoñ (1977), «Da Botica de "Todos os Santos” aos Boticários de "S. José" ", Boletim Clínico dos Hospitais Civis de Lisboa, vol. 37, n. ${ }^{\text {os }} 1-4$, Lisboa, p. 326.

(37) José de Vascóncellos e Menezes (1981), Armadas Portuguesas de Meados do Século XV ao 3. ${ }^{\circ}$ Quartel do Século XVI, Boticas e Boticários de Além-Mar, Lisboa, p. 5; Idem (1987), Armadas Portuguesas, Apoio Sanitário na Época dos Descobrimentos, Lisboa, p. 113; Félix Francisco PAStor Frechoso, op. cit., p. 25.

(38) Manuel das Dores Tello da Fonseca, op. cit., pp.13-18.

(39) Joaquim Verissimo Serrão, História de Portugal, [...], vol. 3, p. 356.

(40) Nancy G. SIRAISI, op. cit., pp. 141-152.

(41) Jacques Le Goff (1991), "As Plantas que Curam", As Doenças Têm História, trad. Laurinda Bom, Lisboa, Terramar, pp. 329-342.

(42) Maria Benedita Araujo (1992), O Conhecimento Empírico dos Fármacos nos Séculos XVII e.XVIII, Lisboa, Cosmos.

(43) Ordenações Manuelinas, Iiv. 5, tít. CIX, Lisboa, Fundação Calouste Gulbenkian, 1984, pp. 316-317. 
(44) Maria Benedita Araújo, op cit., pp. 44-45, passim; J. P Sousa Dias (1993), «A Farmácia e a Expansão Portuguesa (Séculos XVII e XVIII)", A Universidade e os Descobrimentos, Lisboa, pp. 209-227.

(45) Maria Benedita ARaúJo, op cit., pp. 45, passim.

(46) Luís Filipe Barreto (1987), Os Descobrimentos e a Ordem do Saber. Uma Análise Sócio-Cultural, Lisboa, pp. 12-25; Idem (1983), Descobrimentos e Renasciniento. For mas de Ser e Pensar nos Séculos XV e XVI, Lisboa.

(47) Idem, Os Descobrimentos e a Ordem [...], pp. 24-25.

(48) García de ORTa (1987), Colóquios dos Simples e das Drogas da India, fac-símile da ed. de 1891, 2 vols., Lisboa, INCM.

(49) Cristóvão da Costa (1964), Tratado das Drogas e Medicinas das Indias Orientais, int. e notas Jaime Walter, Lisboa.

(50) A Suma Oriental de Tomé Pires e o Livro de Francisco Rodrigues, lei. e notas de Armando Cortesão, Coimbra, 1978, p. 458.

(51) José de Vasconcellos e Menezes, [...] Boticas e Boticários [...]; Idem, [...], Apoio Sanitário, [...] pp. 113-210.

(52) Carlos DA SIlveIRA, "As Boticas a Bordo das Naus de Quinhentos", A Universidade [...], pp. 239-249.

(53) José de Vasconcelos e Menezes, [...] Apoio Sanitário [...], pp. 167-173; P. M. LARANJo CoElho (1922), "A Pederneira. Apontamentos para a Hsitória dos seus Mareantes, Pescadores, Calafates e das suas Construções Navais nos Séculos XV a XVIII", O Archeologo Portuguez, vol. 25, Lisboa, pp. 196-246.

(54) Carlos Martínez Shaw (1993), "Um Microcosmos de Ouro e de Lama", Sevilha, Século XVI, De Colombo a D. Quixote, entre a Evropa e a América - o Coração e as Riquezas do Mundo, trad. Alice Nicolau, Lisboa, Terramar, p. 14

(55) Iria GoNÇALvES, op. cit., p. 12.

(56) A.N./T.T., Chancelaria de D. João III, Oficios, Padrões e Doações, liv. 8, fol. 1 96v.

(57) A.N./T.T., Chancelaria de D. João III, Ofícios, Padrões e Doações, liv. 64, fol. 110

(58) A.N./T.T., Chancelaria de D. João III, Oficios Padrões e Doações, liv. 14, fol. 110.

(59) A.N./T.T., Chancelaria de D. João III, Oficios, Padrões e Doações, liv. 9, fol. 67.

(60) A.N./T.T., Chancelaria de D. João III, Oficios, Padrões e Doações, liv. 25, fol. 158

(61) A.N./T.T., Chancelaria de D. João III, Oficios, Padrões e Doações, liv. 60, fol. 8v.

(62) A.N./T.T., Chancelaria de D João III, Oficios, Padrões e Doações, liv. 70, fol. 204v.

(63) A.N./T.T., Chancelaria de D. João III, Oficios, Padrões e Doações, liv. 69, fol. 178

(64) A.N./T.T., Chancelaria de D. João III, Oficios, Padrões e Doações, liv. 33, fol. 75.

(65) A.N./T.T., Chancelaria de D. João III, Oficios, Padrões e Doações, liv. 25, fol. 114

(66) A.N./T.T., Chancelaria de D. João III, Oficios, Padrões e Doações, liv. 7, fol. 29.

(67) A.N./T.T., Chancelaria de D. João III, Oficios, Padrões e Doações, liv. 33, fol. $21 \mathrm{v}$.

(68) A.N./T.T., Chancelaria de D. João III, Oficios, Padrões e Doações, liv. 69 fol. $185 \mathrm{v}$.

(69) A.N./T.T., Chancelaria de D. João III, Oficios, Padrões e Doações, liv. 71, fol. 379$379 \mathrm{v}$.

(70) A.N./T.T., Chancelaria de D. João III, Oficios, Padrões e Doações, liv. 68, fols. $296 \mathrm{v}-270$.

Asclepio-Vol. XLVI-2-1994 
(71) A.N./T T., Chancelaria de D. João III, Oficios, Padrões e Doações, liv. 65, fols. 2$2 \mathrm{v}$.

(72) A.N./T.T., Chancelaria de D. João III, Oficios, Padrões e Doações, liv. 16, fol. 32.

(73) A.N./T.T., Chancelaria de D. João III, Oficios, Padrões e Doações, liv. 31, fols. $38 \mathrm{v}-39$.

(74) A N./T.T., Chancelaria de D. João III, Oficios, Padrões e Doações, liv. 49, fol. 263v.

(75) A.N./T.T., Chancelaria de D. João III, Oficios, Padrões e Doações, liv. 40, fol. 35v.

(76) A.N./T.T., Chancelaria de D. João III, Oficios, Padrões e Doações, liv. 38, fol. 144.

(77) A.N./T.T., Chancelaria de D. João III, Offcios, Padrões e Doações, liv. 66, fol. 18.

(78) A.N./T.T., Chancelaria de D.João III, Oficios, Padrões e Doações, liv. 62, fol. 27v.

(79) Além dos documentos que a seguir se referem cf. também José DE VASCONCELlos E Meneses, [...] Apoio Sanitário [...], pp.113, passim.

(80) A N./T.T., Corpo Cronológico, parte II, maço 163, doc. 16:

(81) A.N./T.T., Chancelaria de D. João III, Oficios, Padrões e Doações, liv. 26, fol. 51.

(82) A.N./T.T., Corpo Cronológico, parte II, maço 242, doc. 6.

(83) Isabel Maria RibeIRo MEndes (1992), «Acção Religiosa e Assistencial desenvolvida em Chaul no Século XVI», Eborensia, n. ${ }^{\text {os }}$ 9-10, Évora, pp. 153-154.

(84) A.N./T.T., Chancelaria de D. João III, Oficios, Padrões e Doações, liv. 9, fol. 75.

(85) A.N./T.T., Chancelaria de D João III, Oficios, Padrões e Doações, liv. 32, fol. 22.

(86) A.N./T.T., Corpo Cronológico, parte II, maço 204, doc. 107. $128 \mathrm{v}$.

(87) A.N./T.T., Chancelaria de D. João III, Ofícios, Padrões e Doações, liv. 38, fol. 9.

(88) A.N./T.T., Chancelaria de D. João III, Ofícios, Padrões e Doações, liv. 66, fols. 8v-

(89) A.N./T.T., Chancelaria de D. João III, Oficios, Padrões e Doações, liv. 57, fol. $109 \mathrm{v}$.

(90) A.N./T.T., Chancelaria de D. João III, Oficios, Padrões e Doações, liv. 58, fol. 277.

(91) A.N./T.T., Corpo Cronológico, parte II, maço 195, doc. 3.

(92) Isabel Maria Ribeiro Mendes (1990), «O “Deve e o Haver” da Casa da Rainha D. Catarina", Arquivos do Centro Cultural Português, vol. 28, Lisboa-Paris, p. 163.

(93) Gomes de Brito (1907), «As Tenças Testamentárias da Infanta D. Maria», Archivo Historico Portuguez, vol. 5, Lisboa, p. 121.

(94) A.N./T.T., Chancelaria de D. João III, Oficios, Padrões e Doações, liv. 8, fol. 137v.

(95) A.N./T.T., Chancelaria de D. João III, Oficios, Padroes e Doações, liv. 40, fol. 30.

(96) A.N./T.T., Chancelaria de D. João III, Oficios, Padrões e Doações, liv. 54, fols. $340 \mathrm{v}-341$.

(97) Maria Benedita Aires de Almeida Araujo (1989), «Médicos e seus Familiares na Inquisição de Évora", Inquisição. Comunicações apresentadas ao $1 .{ }^{\circ}$ Congresso Luso-Brasileiro sobre Inquisição, vol. 1, Lisboa, pp. 49-72; Idem. (1991), "Os Médicos Portugueses e a Inquisição de Évora", Universidade (s), História, Memória, Perspectivas, Actas do Congresso "História da Universidade», vol. 4, Coimbra, pp. 271-280.

(98) A.N./T.T., Corpo Cronológico, parte II, maço 210, doc. 95.

(99) A.N./T.T., Corpo Cronológico, parte II, maço 242, doc. 5.

(100) A.N./T.T., Chancelaria de D. João III, Oficios, Padrões e Doações, liv. 12, fols. 23-23v. 
(101) A.N./T.T., Chancelaria de D. João III, Oficios, Padrões e Doações, liv. 27, fol. $55 v$.

(102) Mário da Costa Roque, op. cit., p. 131

(103) A.N./T.T., Chancelaria de D. João III, Oficios, Padrões e Doações, liv. 11, fol. $51 \mathrm{v}$

(104) A.N./T.T., Chancelaria de D. João III, Oficios, Padrões e Doações, liv. 11, fol. 19. (105) A.N./T.T., Chancelaria de D. João III, Oficios, Padrões e Doações, liv. 18, fol. 133v.

(106) A.N./T.T., Chancelaria de D. João III, Oficios, Padrões e Doações, liv. 45, fol. 52

(107) A.N./T.T., Chancelaria de D. João III, Oficios, Padrões e Doações, liv. 20, fol. $107 \mathrm{v}$.

(108) A.N./T.T., Corpo Cronológico, parte II, maço 151; doc. 91.

(109) A.N./T.T., Corpo Cronológico, parte II, maço 171, doc. 29.

(110) A.N./T.T., Chancelaria de D. João III, Oficios, Padrões e Doações, liv. 39, fol. 62.

(111) A.N./T.T., Corpo Cronológico, parte II, maço 194, doc. 125.

(112) A.N./T.T., Chancelaria de D. João III, Oficios, Padrões e Doações, liv. 40, fols. $61-62 \mathrm{v}$.

(113) A.N./T.T., Chancelaria de D. João III, Oficios, Padrões e Doações, liv. 69, fols. 110-111v.

(114) A.N./T.T., Chancelaria de D. João III, Ofícios, Padrões e Doações, liv. 40, fol. 214

(115) A.N./T.T., Chancelaria de D. João III, Oficios, Padrões e Doações, liv. 62 fol. $149 \mathrm{v}$

(116) A.N./T.T., Chancelaria de D. João III, Oficios, Padrões e Doações, liv. 47, fol. $29 v$ 